\title{
Introduction: developing thought leadership on managing natural resources
}

We started conceptualizing the idea for this book about five years ago when our first attempts to find management articles on natural resources, how firms acquire and manage them, and whether they inspire specific strategic actions, came up largely empty-handed. Despite having originated expansive fields of research in economics under the umbrellas of natural resource economics (Barnett and Morse, 1963; Hotelling, 1931; Livernois, 2009; Mackellar and Vining, 1989; Reynolds, 1999; Smith, 1978; Stern, 1999) and ecological economics (Ayres, 1996, 2007; Ayres and Talens-Peiro, 2013; Daly, 1992; Georgescu-Roegen, 1973; McMahon and Mrozek, 1997; Young, 1991), as well as having significant traction in the fields of political science and sociology with regards to the relation between natural resources and conflict (Gizelis and Wooden, 2010; Le Billon, 2001, 2004, 2012), topics related to natural resources have largely eluded management scholars.

Our first step towards joining or perhaps even creating and legitimizing a community of management scholars with an interest in this topic was an editorial in the Academy of Management Journal ( $A M J$ ) (George et al., 2015) which is reprinted with permission as the first chapter of this book. In that article, we analysed past research that invokes 'resources' as a broad topic in the Academy of Management Journal, and examined research on natural resources as a context or object of study. As the flagship empirical journal of the management community, articles in $A M J$ discuss impactful and mainstream research topics that represent research endeavours of the scholarly community more broadly. We found that natural resources typically appear in articles that investigate individual roles and effects, attitudes or organizational characteristics and performance (George et al., 2015). However, in those articles, natural resources were most commonly conceived of as purely a context in which to study a research question that was largely unrelated to the natural environment. Hence, explicit theorizing about if and how natural resources affect individual, organizational, and institutional responses seemed to be largely absent. 
With this book, we aim to provide a next step towards bringing natural resource topics into the mainstream management literature. To do so, we invited contributions from scholars around the world and selected ten chapters that paint a diverse picture of how natural resource-inspired research could be conducted within the field of management. It is noticeable that seven of these ten articles are conceptual contributions while the three empirical chapters are all directly or indirectly related to water. Based on our own experience as well, we proffer this exemplifies two focal challenges for research on natural resources.

First, given the nascent state of natural resource research in management, many scholars see a need for conceptualization and theory development before embarking on empirical work. Second, and perhaps more importantly, management researchers in this area face difficulties in getting access to large scale datasets. The three empirical chapters are based on case studies that investigate the arrangements made by a naval explorer that seeks to create unique arctic experiences for its tourist customers (Wigger and Bystrowska, Chapter 5), the sensemaking activities of captains in the Canadian fishing industry (Good, Chapter 9), and the evolving function of a single river (Crawford, Mehra and $\mathrm{Hu}$, Chapter 7). In addition, Miller and Pisani (Chapter 10) use some empirical observations from a Coca-Cola bottling plant in India and water operations by Nestlé in the USA to exemplify how scholars and companies could undertake sustainability science.

Perhaps this preoccupation with water is simply a reflection of its omnipresence or perhaps the attention to water is driven by the fact that it provides a radically different context than other organizational activities, which tend to be land-based. In addition, clean, drinkable water, the impact of water excess and shortages and preserving our oceans are key sustainability challenges that regularly make headlines. Given that climate change for most people remains hard to grasp because of the scale, slowness and longevity of its effects, images and messages of dying barrier reefs, droughts, floods and poor people living in regions without drinkable water tend to more directly appeal to our shared humanity (FAO, 2000; Millman, 2016).

Alternatively, it may also be so that research on other natural resources such as commodities, scarce minerals and metals, and natural resource ecosystems is harder to conduct for management scholars because the databases that typically capture some of these natural resources are better tailored to finance and economics scholars, so that management scholars struggle to find the right data sources to support or falsify their theoretical ideas. Van der Byl and Grøgaard (Chapter 4), for instance, focus on the commodity characteristics inherent to the oil and gas industry. 
After describing the idiosyncratic characteristics of this particular industry, they explore how oil and gas firms use the dynamic capabilities of sensing, seizing and reconfiguring (Teece, 2007) to better manage risk by constantly adapting to turbulent environments and in doing so enhancing their organizational resilience. Using current examples from within and beyond Canada, they explain how firms develop scenario-building skills as a form of sensing the environment (Feiler and Teece, 2014). It is, for instance, remarkable that Shell was the first multinational to produce a corporate social responsibility report in 1998, famously called 'People, Planet, Profit', inspired by the work of John Elkington (1997). Then, these firms seize opportunities by firstly mitigating financial and non-financial risk to ensure access to capital and the stakeholder collaborations needed to access remote locations to initiate exploration activities, while also investing in R\&D to enable next generation technology to be developed and deployed. Using these dynamic capabilities, oil and gas firms are then able to reconfigure their portfolios in line with the turbulent environment while permanently chasing process adjustments to boost efficiency.

Bastian, Richter and Tucci (Chapter 8) also look at commodities and specifically the oil and gas industry in their critical appraisal and extension of the resource-based view (RBV) (Barney, 1991; Hart, 1995). After reviewing the key theoretical claims $\mathrm{RBV}$ proponents make with regards to how resources drive competitive advantage, they combine recent events and theory to show that natural resource deposits like oil and gas fields meet the RBV criteria for sustainable competitive advantage. However, in reality they fall short of generating such advantage. Specifically, they suggest that the constant uncertainty regarding property rights of natural resource deposits, that are always tied to specific geographic locations, results in heightened political risk which can reduce or even annul any competitive advantage (see also Foss and Foss, 2005). In addition, they explore the auto-consumptive nature of natural resources that through use are constantly in a state of decline due to the second law of entropy (Georgescu-Roegen, 1973; McMahon and Mrozek, 1997; Young, 1991). This characteristic is radically different from most resources commonly studied in the RBV such as social capital, trust, knowledge and reputation (Newbert, 2007) that tend to increase in value through use, or offer the possibility of temporary losing value but experiencing a resurgence over time when successfully recombined (Katila and Ahuja, 2002). As such, the authors raise important questions about some of the fundamental assumptions of the RBV (that is, resource permanence and the uncontested nature of resource ownership) that merit additional attention in future research.

A third chapter that looks specifically at commodity industries focuses on industry structure. Departing from a theoretical background rooted 
in the RBV and in transaction cost economics (TCE), Zarea Fazlelahi and Burgers (Chapter 6) explore the importance of firm founding conditions (Stinchcombe, 1965) on the persistence of industry structure. Exploring the theoretical mechanism of the 'management mindset', the authors seek to expose how resource availability, capital intensity, resource accessibility and resource remoteness liken to brownfield sites at time of founding, leaving permanent imprints on the management mindset in the organization that, in turn, have long-lasting effects on industry structure. Specifically, the authors propose that resource abundance, high capital intensity, low accessibility and high remoteness will create a mindset that favours vertical integration and in-house control over specialization and cross-boundary collaboration. In doing so, the authors provide readily testable hypotheses that hopefully will entice researchers to investigate how natural resource characteristics at sensitive periods during which firms are highly susceptible to imprinting, influence both strategic choices made by organizations regarding the organization of their own value chain, as well as broader questions around the structure of industries.

The second chapter of this book builds on research in the natural sciences, engineering and economics to reinterpret the question of scarcity. Schillebeeckx, Workman and Dean (Chapter 2) evaluate the different scarcity frames that have gained prominence since early works in economics (Malthus, 1798; Ricardo, 1817) and that have culminated in the current nexus approach. This recent approach 'comprises the numerous linkages between different natural resources and raw materials that arise from economic, political, social, and natural processes' (Andrews-Speed et al., 2012, p. 5). Building on this new approach, Schillebeeckx and colleagues propose a novel framing of the scarcity agenda in terms of sink resources (the natural biomes that absorb resource extraction's negative externalities) and source resources (the biophysical quantity of natural resources available) that are subject to techno-economic (extraction that is both feasible and affordable), market (ease of trade and efficiency of natural resource markets) and socio-political (the exogenous limits to exploitation imposed by global, national and regional bodies or individual choice) constraints. Their fundamental contribution lies in the clarification of the complex interlinkages between natural resources. This natural resource interdependence fundamentally changes the way we ought to think about scarcity and leads to calls for stimulating organizational flexibility, anti-fragility and collective action.

Three chapters address topics that relate to sustainability and resource exploitation. Miller and Pisani (Chapter 10) dive into questions that relate to accountability and reliability of sustainability claims. Their principal assertion is that existing frameworks to assess sustainability such as the 
Global Reporting Initiative and the United Nations Global Compact lack institutional legitimacy as defined by (Scott, 1995). Unlike prominent ISO standards (for example, 14001 and 9001), the voluntary codes of conduct to which organizations can opt in or out have so far failed to become de facto industry standards as their uptake has been very limited. While acknowledging the possibility that the EU will soon start enforcing GRI reporting for many firms, the authors contend that 'sustainability science', an emergent method rooted in the scientific method is better suited to become institutionalized because it borrows from the widely accepted scientific approach and because it asks fundamental questions that need be answered, rather than allowing organizations to decide what is worth reporting and what not. Building on some emergent findings from a comparative case study analysis, the authors demonstrate how sustainability science could prove to be a valuable method through which organizations, NGOs, and scholars could meaningfully respond to the question of whether 'sustainable' practices are truly sustainable.

Without explicitly relating to the notion of sustainability science, Lee, Reinhardt, Keller, Gurtner and Schiffer (Chapter 3) provide an example of how a sustainable science approach to resource substitution could work. Through a cross-disciplinary collaboration of engineers and management scholars, the authors show how organizational and governmental decision makers struggle with conflicting goals, captured by the trilemma of competitiveness, supply security and sustainability in Germany. The chapter focuses on the complex problems associated with transitioning toward a low-carbon economy in the chemical industry while maintaining global competitiveness. Using a cradle-to-gate approach consisting of flow-sheet simulations, life cycle analysis, and an economic analysis of capital investment and operating costs, the authors explore the information available to decision makers when it comes to deciding which raw material to use in chemical industry.

It is our hope that this book will entice a community of scholars to engage in collaborative efforts to create such databases with a view to stimulating more empirical research on complex natural resource phenomena in management.

\section{MANAGEMENT AND THE SUSTAINABLE DEVELOPMENT GOALS}

In the last editorial of Gerry George's tenure as editor of Academy of Management Journal, the editorial team developed a framework to help structure management thinking around Grand Challenges, defined as 
'specific critical barrier(s) that, if removed, would help solve an important societal problem with a high likelihood of global impact through widespread implementation' (George et al., 2016, p. 1881). They proposed that the United Nations' Sustainable Development Goals (SGDs), signed by 193 member states in September 2015, provide a globally accepted overview of the focal challenges facing the world and set 169 specific targets to be achieved by 2030 at latest. More than half of these sustainable development goals have direct implications for the management of natural resources (see Table I.1). The importance of natural resource-related sustainable development goals provides a powerful indication that this topic should no longer elude management scholars.

From a firm perspective, solving these grand challenges provides impressive opportunities for growth and organizational innovation. Working towards zero hunger (SDG 2) has implications for all companies involved in agriculture and the food industry. How to create business models that are able to serve the poorest people in the world, often in rural and remote areas, is logistically and organizationally challenging. Such business models have to be firmly embedded in high cost efficiencies to be able to sell sufficient quantities at low prices so that foodstuffs reach those in need and remain affordable. Firms can collaborate with governments and NGOs when these are present and reliable or step in where governments fail to address basic needs. This idea is not new - over 30 years ago, Peter Drucker stated that "the proper "social responsibility" of business is to tame the dragon, that is to turn a social problem into economic opportunity' (Drucker, 1984, p. 62). Those firms that manage to 'tame the dragon' in a profitable way flourish and learn valuable lessons that are reproducible in other contexts, enabling them to engage in reverse innovation (Govindarajan and Ramamurti, 2011). Organizations can also take a different approach and focus on developing new business models that support - through education and provision of necessary inputs - local production and help the disadvantaged make a living wage within their communities. Building networks across the poorest regions through which local communities can reach output markets otherwise unimaginable can provide the economic stimulus needed to eliminate hunger.

As hinted at by Miller and Pisani (Chapter 10), clean water and sanitation provide an important area in which companies can be real assets to solving SDGs or can make problems significantly worse. As Coca-Cola faced community uprisings linked to their alleged overexploitation of underground water reservoirs in India, the company decided to seize operations even though the state's High Court would eventually rule in their favour. Every company that relies on water as a key resource is susceptible to being challenged for overexploitation of what many people see 

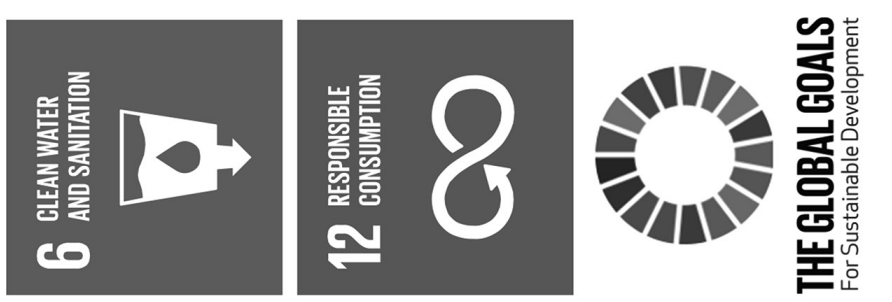

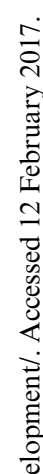
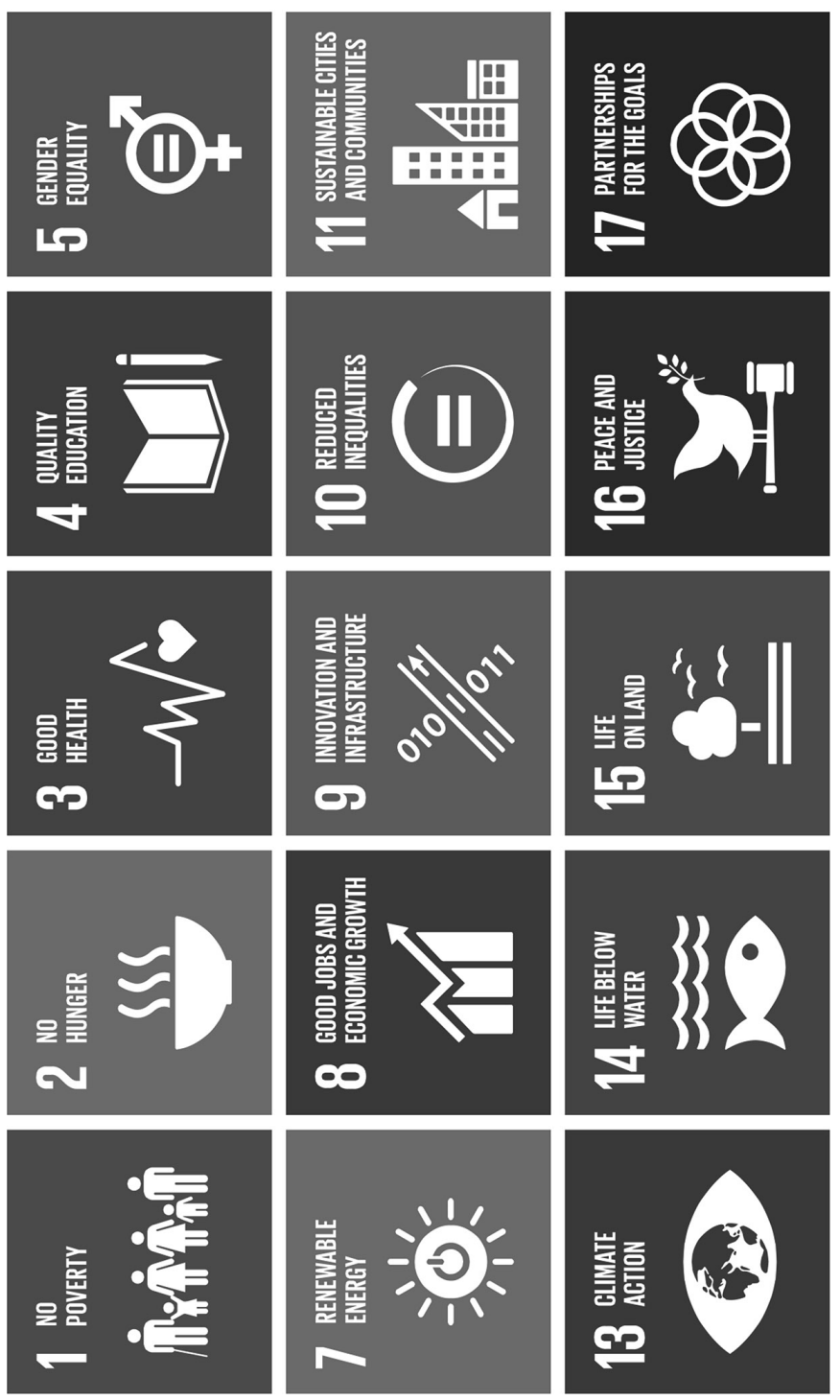

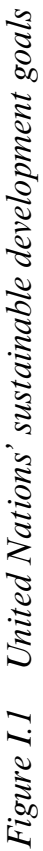




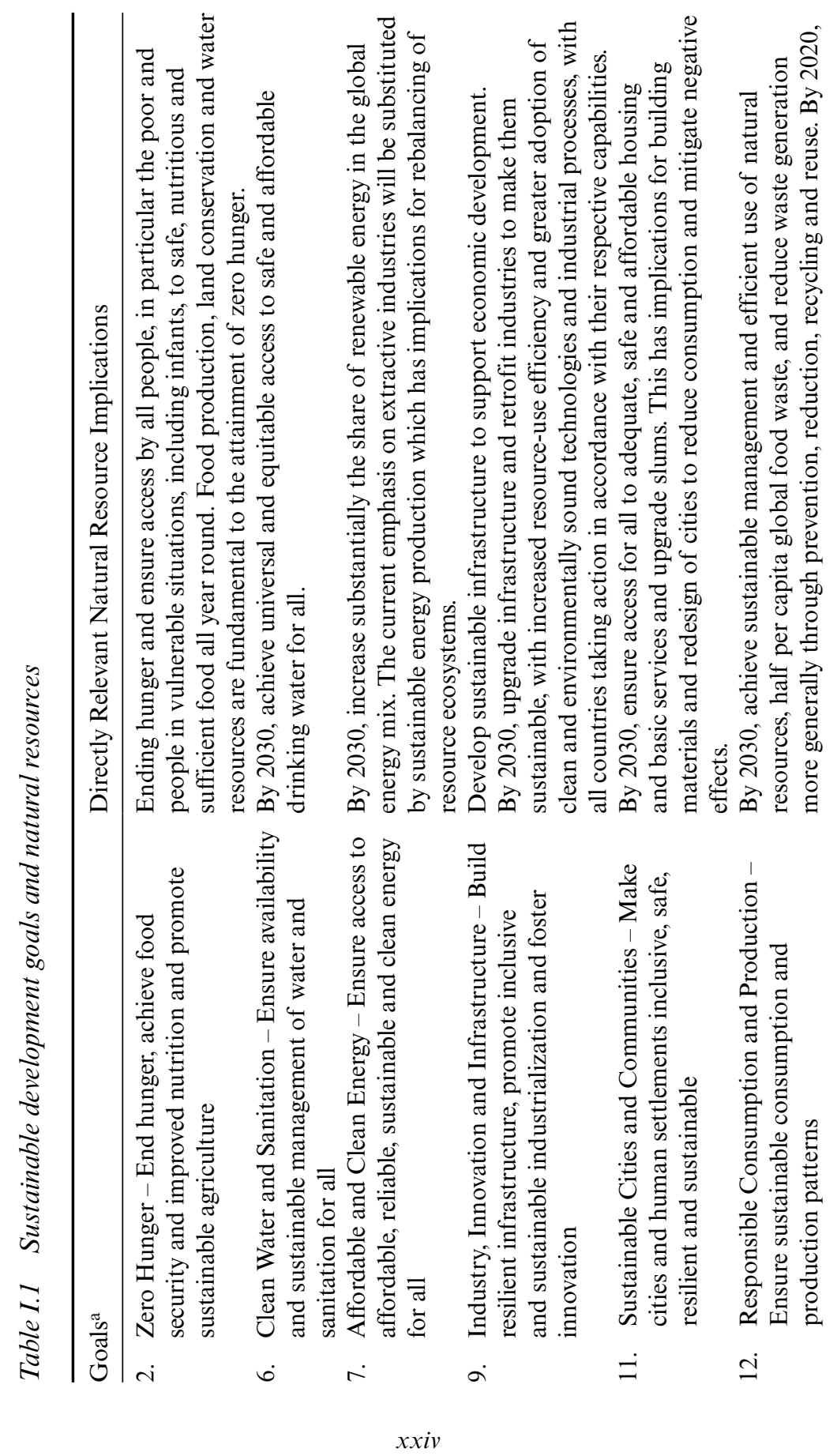



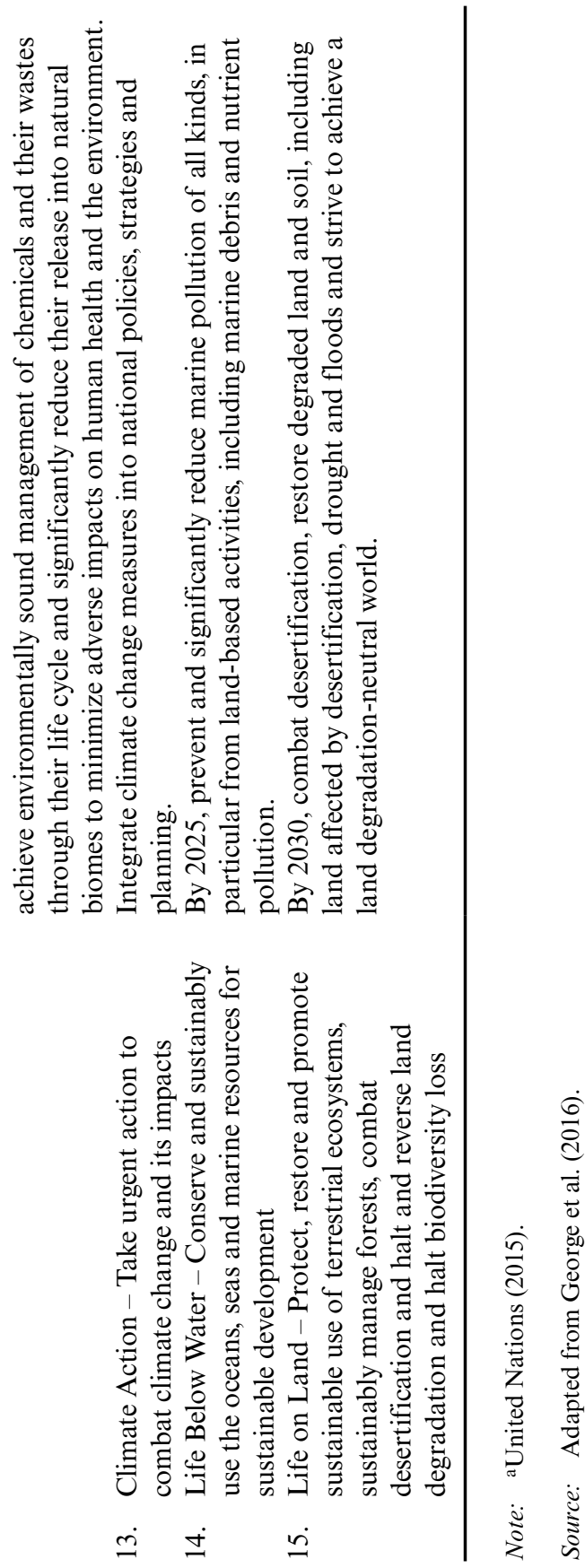
as a human right and a public good. Improving access to potable water and sanitation by building infrastructure that meets local needs is an essential step in achieving the 2030 SDGs. In addition, companies continue to invest in desalination and other techniques that could help address the supply limitations of drinkable water in a sustainable manner. While current desalination techniques tend to require large amounts of energy, thus creating other sustainability challenges, continued research efforts into this area are required to address this challenge. The company that develops the technology to desalinate water in a cost- and environmentally effective way will have a massive market opportunity to exploit for years.

The same goes for SDG 7, which focuses on affordable and clean energy. As prices for wind, solar, geothermal and other alternative energy sources keep dropping and become increasingly competitive in many countries, the race is still on to further exploit renewable energy sources and invent ways to stabilize electricity supply in ways that truly reduce fossil fuel dependence, not only in transportation but also in our buildings and industries (IRENA, 2017). With annual investment in renewables increasing from about 50 billion USD in 2004 to a record 348 billion USD in 2015 (investment did drop in 2016 as countries started to invest more in ensuring that the electricity grids can cope with the recent influx of renewable sources (Janssen, 2017)), countries all over the world are making substantial efforts to reduce carbon emissions from fossil fuel combustion. Despite these investments in decarbonizing the economy, climate scientists are issuing increasingly starker warnings about the need to do significantly more to prevent dramatic climate change. The 2015 Paris Agreement still provides a beacon of hope that the world will come together to tackle this existential threat. For businesses, the potential returns for innovations that fit into a clean energy ecosystem are likely to be huge and those that have betted heavily on this emerging ecosystem, like Tesla with its Gigafactory, are likely to benefit handsomely.

SDG 9 challenges industry to develop more sustainable physical infrastructure, to retrofit existing industries to make them more sustainable and resource efficient, to increase the number of $\mathrm{R} \& \mathrm{D}$ workers per capita, and to further improve access to ICT and specifically the Internet around the world. Improving the sustainability of the built environment, roads and rails, airports and harbours will be instrumental to avoid dramatic climate change. The European Commission defines resource efficiency as 'using the Earth's limited resources in a sustainable manner while minimising impacts on the environment. It allows us to create more with less and to deliver greater value with less input' (European Commission, 2017). Resource efficiency is thus a business decision to make the best possible use of natural resources, reducing or eliminating waste from the production process. A study conducted by the 
European Environment Agency (Kazmierczyk et al., 2016) found that overall resource use in the European Union fell in both absolute (12 per cent) as well as relative terms (from 15.5 to 13.1 tonnes per person) between 2000 and 2014, driven by economic imperatives and the desire to increase competitiveness, to secure the supply of raw materials and energy and reduce dependence on imports, and to lower pressures on the environment.

While the overarching legal framework within Europe is defined at the transnational level, different institutions implement policies in different ways with varying effects. Exchanging best practices across boundaries will be essential in ensuring this positive trend towards lower material use is not reversed if economic growth starts picking up again. The contribution of Lee et al. (Chapter 3) provides a nice example of how the use of different resources can be compared using life cycle analysis in which the current state of affairs is compared to alternative scenarios from an economic and environmental perspective.

In the same vein, attention needs to be paid to creating and nourishing more sustainable cities and communities (SGD 11), which will require low-carbon building materials in both the richest cities on earth as in the slums. Beyond the use of insulation, energy-efficient building techniques and other ways of passively maintaining temperatures at a comfortable level in buildings, city planners need to pay attention to how people are intended to move around within the city. Ideally, most amenities should be easily accessible by foot, bike or public transport so that local community businesses can be supported while at the same time reducing the need to drive around for miles to find basic foodstuffs. Given the ever-growing percentage of the global population that lives in cities, investing in the sustainability of these concrete jungles is essential for quality of human life and human health.

SGD 12 and 13 focus on responsible consumption and production and on taking climate action. They fit within the same lines of reasoning as SGDs 9 and 11. Increasingly, institutional, societal and regulatory pressures will drive companies towards reducing their environmental footprint, investing in climate neutral or even climate positive technologies, and to reduce their own wastage of energy, water and natural resources. In addition, internal drivers such as management conviction and employee engagement can also push companies in the same direction. The drive towards a more circular economy in which products are reused or recycled at their end-of-life, changes the fundamental product life cycle in such a way that explicit considerations of how the product can be dismantled and (partially) reused after it reached the end of its productive life need be included in the design of the product itself (Anderson and Zeithaml, 1984; McDonough and Braungart, 2002). 
Another grand challenge is whether businesses can become advocates for responsible consumption. From an environmental sustainability perspective, the richest 10-20 per cent of global population will inevitably need to reduce their reliance on fossil fuels and thus most likely they will need to make some lifestyle changes as well. One frequently mentioned example would be to move towards a less meat-intense diet, especially reducing the production of cows. Besides considerations around animal welfare advocated by animal rights groups like PETA, ecologists and climate scientists have shown that the meat industry has a very substantial and negative impact on the climate due to its reliance on large grasslands, the feed produced specifically for slaughter animals and the methane exhaust largely caused by cows.

Supporting life below water (SGD 14) focuses on the need to reduce marine debris, nutrient pollution and to protect marine ecosystems. The challenges associated with sustainable fishing and arctic tourism, as touched upon by respectively Good (Chapter 9) and Wigger and Bystrowska (Chapter 5) need be addressed to meet this goal. The constraints imposed on captains to catch specific fish and to throw away bycatch do, from an outside perspective, not seem like the most sustainable solution. Arctic tourism is characterized by a tenuous balance between the environmental damage done by tourists and by fuel-burning boats and the money such tourists bring in that can support arctic conservation or provide an additional source of income for local communities. When it comes to the oceans themselves, significant local and global efforts are required to cleanse them of plastic (epitomized by the plastic vortex or the Great Pacific garbage patch) to support marine life (Harse, 2011), and to counter the effects of global warming on the coral reefs all over the world, most notably the Australian Great Barrier Reef (Ainsworth et al., 2016; De'ath et al., 2012; Evans et al., 2016). In addition, the debate about whether or not the dumping of filtered nuclear water in the Pacific following the Fukushima disaster is environmentally acceptable remains ongoing (Mathiesen, 2016; West, 2016).

Finally, by 2030 SGD 15 aims to achieve a land-degradation-neutral world as well as further promote the protection of terrestrial ecosystems, combat desertification and manage forests sustainably. While international organizations such as the Rainforest Alliance and the Forest Stewardship Council have been around for quite some years and have helped companies make significant progress when it comes to sustainable sourcing of wood products, for many other resources (including land), such organizations are non-existent or lack institutionalization. In these areas, companies can use non-market strategies and position themselves as frontrunners to create a reputational advantage and earn a long-term social license to operate. 


\section{FUTURE RESEARCH AVENUES}

The Grand Challenges editorial (George et al., 2016) introduced an overarching framework that explored linkages between multiple categories with research topics for management scholars to explore. How to articulate a grand challenge is essential to create a shared understanding of the problem and fundamentally influences how one might conceive of solutions. Schillebeeckx et al. (Chapter 2) make the point that how the scarcity debate is framed has evolved throughout the previous centuries and propose a new and current framing based on nexus thinking. Nexus thinking is based on the still largely unknown interconnections that exist between source and sink resources and acknowledges the complex feedback loops that govern the natural environment. It leads to advocacy for a level of precaution that is typically not associated with industry and underlines the importance of developing anti-fragile organizations that not simply withstand turbulent environments but also become stronger when they are tested, like an organic immune system (Taleb, 2012).

A second key aspect of dealing with grand challenges is that they require action at multiple levels, from the individual to the transnational. While we did not ask for this specifically, the contributions represented in this book exemplify the need to think about natural resources and their implications across multiple levels. Presse and Paetzold (Chapter 11), for instance, discuss the need for an emission-based trading system that requires a supranational authority like the UN to implement a system that entails global redistribution of wealth from those responsible for the combustion of fossil fuels to those that are not. Lee et al. (Chapter 3) investigate the needs of a particular sector at the country-level and study the implications of switching one resources for various alternatives from an ecological and economical perspective. Crawford, Mehra and Hu (Chapter 7) investigate the natural ecosystem around a river and how various institutions, organizations and individuals have shaped and reshaped its meaning over time. Van der Byl and Grøgaard (Chapter 4) study how firms in gas and commodity markets should manage risks they face due to their exposure to natural resources. Similarly, Bastian, Richter and Tucci (Chapter 8) focus on how firms in fossil fuel markets can gain sustainable competitive advantage and seek to explain why the resource-based view's VRIN conditions (Barney, 1991) do not capture the entire picture. No chapters focusing on the level of individual responses to natural resources were withheld throughout the selection process. Zarea Fazlelahi and Burgers (Chapter 6) present the managerial mindset as a mediator for how resource conditions during founding periods imprint on long-term strategic choices regarding vertical integration made by firm decision makers. 
As most of the chapters are conceptual or are case studies, the outcomes and impact the authors have focused on have typically been limited to firm-centric measures of success such as competitive advantage (Chapter 8 ), vertical integration (Chapter 6) and risk management and adaptation (Chapter 4). While some contributions have looked more generally at what a specific change would mean for the society at large, for instance, with regards to environmental footprint (Chapter 3) or for global poverty and carbon reduction (Chapter 11), little attention has been paid to what metrics would be applicable to measure the performance of organizations with regards to natural resources. Chapter 10 comes closest to this ambition in that it proposes a framework of questions that companies should ask themselves if they want to engage in sustainability science, and the answers to these questions could inspire metrics that become valid and verifiable.

Overall, this book exemplifies the current state of knowledge and debate about natural resources in management. What is written and omitted in the chapters reveals useful avenues for future research and calls for empirical evidence: (a) that frame natural resources and their inherent challenges using varied theoretical lenses, (b) across multiple levels of analysis (individual, community, firm, industry, ecosystem) that each serve to investigate specific roles, problems and opportunities, (c) through developing novel and distinct ways of addressing those challenges and opportunities and (d) across outcomes and impact assessments that are elusively defined in terms of corporate goals or occasional normative statements. We hope this book will provide a stepping stone for research that aims to solve grand challenges related to natural resources, and will prove to be a milestone in building a global community of researchers to undertake this important task. As management scholars, there is no better possible time to enter this debate within our work as educators, researchers, consultants and policy advisors than right now.

\section{REFERENCES}

Ainsworth, T.D., S.F. Heron, J.C. Ortiz, P.J. Mumby, A. Grech, D. Ogawa and W. Leggat. (2016), 'Climate change disables coral bleaching protection on the Great Barrier Reef'. Science, 352(6283), 338-2.

Anderson, C.R. and C.P. Zeithaml. (1984), 'Stage of the product life cycle, business strategy, and business performance'. Academy of Management Journal, 27(1), $5-24$.

Andrews-Speed, P., R. Bleischwitz, T. Boersma, C. Johnson, G. Kemp and S.D. VanDeveer. (2012), The Global Resource Nexus: The Struggles for Land, Energy, Food, Water, and Minerals, Washington DC, USA: Transatlantic Academy, 
Washington - Retrieved from: http://www.transatlanticacademy.org/publications/ global-resource-nexus- $\%$ E2 $\% 80 \% 93$-struggles-land-energy-food-water-and-miner als (accessed 15 August 2017).

Ayres, R.U. (1996), 'Technology, progress \& economic growth'. European Management Journal, 14(6), 14.

Ayres, R.U. (2007), 'On the practical limits to substitution'. Ecological Economics, 61, 14.

Ayres, R.U. and L. Talens-Peiro (2013), 'Materials efficiency: Rare and critical metals'. Philosophical Transactions of the Royal Society A, 371(1986), 1-21. doi:10.1098/rsta.2011.0563.

Barnett, H.J. and C. Morse. (1963), Scarcity and Growth: The Economics of Natural Resource Availability, Baltimore, MD: Johns Hopkins University Press for Resources for the Future.

Barney, J.B. (1991), 'Firm resources and sustained competitive advantage'. Journal of Management, 17(1), 99-120.

Daly, H. (1992), 'Is the entropy law relevant to the economics of natural resource scarcity? - Yes of course it is!'. Journal of Environmental Economics and Management, 23, 5.

De'ath, G., K.E. Fabricius, H. Sweatman and M. Puotinen. (2012), 'The 27-year decline of coral cover on the Great Barrier Reef and its causes'. Proceedings of the National Academy of Sciences, 109(44), 17995-9.

Drucker, P.F. (1984), 'Converting social problems into business opportunities: The new meaning of corporate social responsibility'. California Management Review, 26(2), 53-63.

Elkington, J. (1997), Cannibals with Forks: The Triple Bottom Line of Twenty First Century Business, Oxford: Capstone Publishing Ltd.

European Commission. (2017, 24/01/2017). Resource Efficiency. Retrieved from http://ec.europa.eu/environment/resource_efficiency/index_en.htm (accessed 15 August 2017).

Evans, L.S., C.C. Hicks, W.N. Adger, J. Barnett, A.L. Perry, P. Fidelman and R. Tobin. (2016), 'Structural and psycho-social limits to climate change adaptation in the Great Barrier Reef Region'. PlOS ONE, 11(3), e0150575.

FAO. (2000), Crops and Drops: Making the Best Use of Water for Agriculture, Rome, Italy - Retrieved from: ftp://ftp.fao.org/docrep/fao/005/y3918e/y3918e00. pdf (accessed 15 August 2017).

Feiler, P. and D. Teece. (2014), 'Case study, dynamic capabilities and upstream strategy: Supermajor EXP'. Energy Strategy Reviews, 3, 14-20.

Foss, K. and N.J. Foss. (2005), 'Resources and transaction costs: How property rights economics furthers the resource-based view'. Strategic Management Journal, 26(6), 541-53.

George, G., S.J.D. Schillebeeckx and T.L. Liak. (2015), 'The management of natural resources: An overview and research agenda'. Academy of Management Journal, 58(6), 1595-613.

George, G., J. Howard-Grenville, A. Joshi and L. Tihanyi. (2016), 'Understanding and tackling societal grand challenges through management research'. Academy of Management Journal, 59(6), 1880-95.

Georgescu-Roegen, N. (1973), 'The entropy law and the economic problem'. In H. Daly (ed.), Toward a Steady State Economy, San Francisco: Freeman.

Gizelis, T.-I. and A.E. Wooden. (2010), 'Water resources, institutions, \& intrastate conflict'. Political Geography, 29(8), 444-53. 
Govindarajan, V. and R. Ramamurti. (2011), 'Reverse innovation, emerging markets, and global strategy'. Global Strategy Journal, 1(3-4), 191-205.

Harse, G.A. (2011), 'Plastic, the Great Pacific garbage patch, and international misfires at a cure'. UCLA Journal of Environmental Law \& Policy, 29, 331.

Hart, S.L. (1995), 'A natural-resource-based view of the firm'. Academy of Management Review, 20(4), 29.

Hotelling, H. (1931), 'The economics of exhaustible resources'. Journal of Political Economy, 29(2), 137-75.

IRENA (2017). REthinking Energy 2017, Masdar City, Abu Dhabi - Retrieved from: http://www.irena.org/DocumentDownloads/Publications/IRENA_REthin king_Energy_2017.pdf (accessed 15 August 2017).

Janssen, R. (2017, 04/01/2017). 'Global investment in renewable energy dropped in 2016'. Retrieved from https://energyindemand.com/2017/01/14/global-invest ment-in-renewable-energy-dropped-in-2016/ (accessed 15 August 2017).

Katila, R. and G. Ahuja. (2002), 'Something old, something new: A longitudinal study of search behavior and new product introduction'. Academy of Management Journal, 45(6), 1183-94.

Kazmierczyk, P., T. Geerken, B. Bahn-Walkowiak, I. Vanderreydt, J. v. Veen, M. Veneziani and M. Arnold. (2016), 'More from less: Material resource efficiency in Europe; 2015 overview of policies, instruments and targets in 32 countries'.

Le Billon, P. (2001), 'The political ecology of war: Natural resources and armed conflicts'. Political Geography, 20, 24.

Le Billon, P. (2004), 'The geopolitical economy of "resource wars". Geopolitics, 9(1), 1-28.

Le Billon, P. (2012), Wars of Plunder: Conflicts, Profits and the Politics of Resources, New York: Columbia University Press.

Livernois, J. (2009), 'On the empirical significance of the Hotelling rule'. Review of Environmental Economics and Policy, 3(1), 22-41. doi:10.1093/reep/ren017.

Mackellar, F.L. and D.R. Vining (1989), 'Measuring natural resource scarcity'. Social Indicators Research, 21(5), 517-30. doi:10.1007/bf00513459.

Malthus, T.R. (1798), An Essay on the Principle of Population, New York: Cosimo (Vol. 1).

Mathiesen, K. (2016), 'Is it safe to dump Fukushima waste into the sea?'. The Guardian. 13/04/2016 accessed 23/02/2017. Retrieved from https://www.the guard ian.com/environment/2016/apr/13/is-it-safe-to-dump-fukushima-waste-into-thesea (accessed 15 August 2017).

McDonough, W. and M. Braungart. (2002), Cradle to Cradle: Remaking the Way We Make Things, New York: North Point Press.

McMahon, G.F. and J.R. Mrozek (1997), 'Economics, entropy and sustainability'. Hydrological Sciences Journal - Journal Des Sciences Hydrologiques, 42(4), 501-12. doi:10.1080/02626669709492050.

Millman, O. (2016), 'The Great Barrier Reef is under severe stress - but not dead yet'. The Guardian. Retrieved from https://www.theguardian.com/us-news/2016/ oct/14/great-barrier-reef-severe-stress-not-dead-yet (accessed 15 August 2017).

Newbert, S.L. (2007), 'Empirical research on the resource-based view of the firm: An assessment and suggestions for future research'. Strategic Management Journal, 28(2), 121-46. doi:10.1002/smj.573.

Reynolds, D.B. (1999), 'The mineral economy: How prices and costs can falsely signal decreasing scarcity'. Ecological Economics, 31(1), 155-66. doi:10.1016/ s0921-8009(99)00098-1. 
Ricardo, D. (1817), On the Principles of Political Economy and Taxation, J. Murray (ed.). Retrieved from www.econlib.org/library/Ricardo/ricP.html (accessed 15 August 2017).

Scott, W.R. (1995), Institutions and Organizations, Thousand Oaks, CA: Sage (Vol. 2).

Smith, V.K. (1978), 'Measuring natural resource scarcity - theory and practice'. Journal of Environmental Economics and Management, 5(2), 150-71. doi:10.1016/0095-0696(78)90024-4.

Stern, D.I. (1999), 'Use value, exchange value, and resource scarcity'. Energy Policy, 27(8), 469-76. doi:10.1016/s0301-4215(99)00043-9.

Stinchcombe, A.L. (1965), 'Organizations and social structure'. Handbook of Organizations, 44(2), 142-93.

Taleb, N.N. (2012), Antifragile: Things that Gain from Disorder, London: Penguin Group.

Teece, D.J. (2007), 'Explicating dynamic capabilities: The nature and microfoundations of (sustainable) enterprise performance'. Strategic Management Journal, 28(13), 1319-50.

West, T. (2016). 'Japan plans to release thousands of tons of Fukushima waste into the Pacific, with highly radioactive waste under seabed'. Inquisitr. 19/04/2016 accessed Retrieved from http://www.inquisitr.com/3013081/japanplans-to-release-thousands-of-tons-of-tritium-laced-fukushima-waste-into-thepacific-with-highly-radioactive-waste-under-seabed/ (accessed 15 August 2017).

Young, J.T. (1991), 'Is the entropy law relevant to the economics of natural resource scarcity?'. Journal of Environmental Economics and Management, 21(2), 169-79. doi:10.1016/0095-0696(91)90040-p. 
Gerard George and Simon J.D. Schillebeeckx - 9781786435729 Downloaded from PubFactory at 04/26/2023 10:24:53AM 